\title{
Workforce Big Data Analytics and Production Efficiency: A Manager's Guide
}

\author{
Karibo Benaiah Bagshaw \\ Department of Management \\ Rivers State University of Science and Technology \\ Port Harcourt, Nigeria. \\ Joy Amina Okpakpam \\ Department of Management \\ Rivers State University of Science and Technology \\ Port Harcourt, Nigeria.
}

\begin{abstract}
The study investigates the use of workforce big data analytics as a tool to guide production managers to boost production efficiency while also ascertaining the level of awareness in the use workforce analytics amongst production managers. The study adopted survey research design and questionnaire were distributed to 20 respondents comprising of all Production Managers of the 20 Manufacturing Companies understudied. Data generated was analyzed using averages and scores. The outcome of the analyses showed that only $30 \%$ of the manufacturing companies had established and understood workforce plan while $\mathbf{7 0 \%}$ did not have. Again the study showed that only $\mathbf{2 5 \%}$ production managers agreed that the use of workforce big data analytics is necessary to boost production efficiency. Further findings showed that $75 \%$ of the managers admitted that their production was below average of which $40 \%$ of the managers ascribed their dismal performance to excessive manpower downtime which is a by-product of workforce scheduling. Based on the findings, it can be concluded that the use of workforce big data analytics is a more significant and important factor in boosting production efficiency.
\end{abstract}

Keywords: Big data, capacity utilization, employee productivity, production efficiency, workforce,

\section{INTRODUCTION}

The world has gradually evolved into a global entity and firms are striving to keep afloat of the ever increasing demand to withstand competition and remain in business through attaining and maintaining efficiency in production. Remaining in business will mean having an edge over competitors and maintaining a large market share by satisfying the customers. To achieve this, organizations have adopted several strategies such as total quality management, six sigma etc and other production and expansion strategies, yet there seems not to be a satisfying answer to this age long challenge of keeping a firm in the lead at the market place. Even when firms succeed in adopting a strategy that helps it work through becoming a market leader, it's not able to maintain the position for long, thus the search for better a strategy continues. The big question then is; 'what are they not doing right' or 'how can firms enhance production to maintain or expand their market share'.

In addressing the issue of maintaining competitive advantage, Porter (1998) proposed that the basis of competitive advantage is on the organizational resources categorized as; human resources, knowledge resources, natural resources, capital resources and infrastructural resources. Du Plessis (2009) posited that the human resource is one of the organization's most 
effective and valuable resources. Following his position, it becomes imperative for organizations to formulate and execute strategies that will boost the performance of their workforce to achieve efficiency in production.

One of the strategies adopted by successful organizations like Deliotte has been the use of workforce big data or analytics in managing its workforce. With the evidence based outcome achieved by Deliotte, lots of organizations like Biogen have embraced the use of big data analytics in their workforce management in order to boost the efficiency of their production process.

\section{The Problem}

Organizations need to attain efficiency in production in order to satisfy their customers. Also, the need to reduce waste and loss of man hour and at the same time boost performance of the workforce in the production process contributed to why this study was carried out.

\section{The Question}

To what extent does workforce big data analytics influence production efficiency?

\section{The Workforce metric}

The start off point in understanding the workforce big data analytics is to understand what the workforce metric is. This is because workforce metrics is the basis upon which workforce analytics is carried out.

Missildine (2013) gave an overview of what workforce or human resource metric is, stating that workforce metric is the data used to calculate the cost implication of talent management practices and human resource processes to ascertain the success of HR programs. She emphasized that the place of metrics in adding value to organizations is by making available the information the organization need to make precise decisions about their workforce. According to her, metrics informs the decision maker on current and past data for the workforce management such as employee engagement, performance and retention. For example "Our average hiring time is 90\%," "Our annual attrition rate is 20\%," "Our highest performance score is 70\%." She further posits that although metrics monitor activity, it doesn't necessarily give insight to a causal relationship. Like the example earlier, those metrics are not enough to know what limits recruitment, what brings about attrition or what enhances performance. Workforce metrics are said to be data (numbers) that reveal some vivid detail about given processes or outcomes (Carlson and Kavanagh, 2011).

\section{The Workforce Big Data Analytics}

Although the big data concept may be a relatively new concept in business, it has been in use for a while without any descriptive name to it. For the past few years, it has made a buzz in business, particularly in the area of sales and finance. Despite being a buzz word in the business world today, it still remains an unknown or 'never-heard-of' term for a lot of persons and this has brought about some confusion to the term 'big data'. Due to these confusions and misinterpretations surrounding the big data concept, it is important to ask if every chief officer or strategist in organisations are on the same page with what it is, and stands for? Therefore the question needs to be asked about what the big data means.

What precisely comes to play in our minds when the 'big data' concept is mentioned? Do we see it as just a data that is very huge, cumbersome, voluminous or too weighty for download, assessing and accessing? Well, it may not necessarily follow these connotations. 
The big data is referred to as a buzzword, or catch-phrase, that illustrates or depicts a substantial quantity of organized and unorganized data that is too large and complex to manage using conventional filing system and software methods (Beal, 2015). This shows that big data is a budding term that explains any voluminous amount of structured, semi-structured and unstructured data that has the potential to produce valuable information when explored.

The big data buzz has gradually made its way into the human resources arena and is being accepted with a lot of enthusiasm judging from the numerous empirical studies in the subject area (Lawler, Levenson and Boudreau, 2005; Ulrich, 2013; Bassi, 2011). The talk about big data in the human resource arena means making use of big data analytics in workforce management. It has become imperative that human resource management professionals clinch it with enthusiasm. This implies that where the management of workforce is concerned, big data becomes a big deal because it empowers employers and human resources managers to make more knowledgeable and up-to-date business decisions. It helps to reveal significant information and offer fact based insights that point the decision maker to corrective action thus bringing about informed decisions that will boost efficiency and enhance productivity.

The Big data analytics for workforce management is often referred to as workforce analytics. It is the process of looking at workforce metrics with the aim of searching for trends, patterns, correlations and insights about human behavior (Fitz-Enz and Mattox, 2014). Generally, analytics identify patterns of connections linking metrics. Its goal is to reveal what the firm didn't know and to position the firm to be predictive when it comes to workforce management functions like hiring, training and work scheduling. It creates the backdrop against which firms use to reduce non-productive paid time by helping the firm to boost workforce utilization without increasing costs. The ultimate goal is to make labor performance improvement decisions that lead to enhanced workforce effectiveness. The result is better use of labor resources while maintaining quality output.

I believe the big data trend in workforce management is here to stay because as firms search for ways to reduce waste and improve production, they are required to look past the usual workforce measurements such as attendance rate, output logged in time etc in order to understand the link among resources such as machines, work-in-progress and labor. This is necessary because, by investigating or studying how the workforce and machines combine to bring about production goals, firms can build a lasting competitive advantage and achieve production efficiency. Applying the concept of workforce big data analytics in achieving production efficiency significantly centers on scheduling and other workforce related practices to maximize the capabilities of the workforce.

\section{Workforce Scheduling}

According to William (2012), scheduling the workforce is an important assignment in capacity management. Capacity management on the other hand, entails the scheduling and management of system competency and performance in order to equate the intensity of operations with the intensity of demand. It is the uncertainty of demand level that gives rise to the problem of determining the level of workforce and the big-data matrices in arriving at an optimal level of workforce that will maximize production efficiency. Everett, Eatherley and Slater, (1992) stated that the workforce level constitutes the number of productive employees required in a productive system. It is the determined number of employees required for each period's output requirement. They explained that what determines the workforce level in any system is the level of output on demand. This means workforce level increases as output increases and decreases as output decreases. 
This method of scheduling workforce involves investment in multi-job training that will enable labour to be effective and efficient in handling work operations. However, this results to lower performance during learning periods. Another strategy of scheduling workforce is to maintain a constant workforce size where there is high specialized division of labour. During periods of low-demand, the workforce should be scheduled such that only the forecasted amount is produced, thereby giving room for idle working hours. In times of high-demand, extra work hours would be required to meet the demand intensity. The implication of this is that the utilization of the workforce would vary from high to low at different times. An important advantage of this strategy is the avoidance of hiring and lay-off cost. The task of scheduling workforce therefore, is to make sure that a good number of people are working at any point in time to provide a capacity appropriate for the level of demand at that point in time.

However, it is the responsibility of the management of the firms to determine the capacity of production and the required workforce needed to meet with the changing attitudes towards demand.

In view of the foregoing findings and conclusions, the following recommendations are made: that in order to minimize the level of impact of demand uncertainties on production scheduling and workforce level, periodic scheduling of production capacity taken week by week adopting a uniform workforce level. Differences in output levels and actual demand can be taken care of by overtime, backorders and subcontracting where demand is far in excess of output. In cases of lower demand level compared to the output level, then excess output can be accommodated as inventory but care must be taken as to avoid inventory build-up bearing in mind total inventory cost. Also, in a situation where the demand for the firms' product is low, the firm should employ the just-in-time system of scheduling production. For minimizing total production cost production scheduling with the required workforce should be commensurate with the level of demand of the firms' products.

The workforce levels are often altered to equate with production and demand requirement through varying processes such as hiring, firing or lay off of production employees. Determining the intensity of labour in production operations relies on the strategic approach adopted in hiring and layoff. Decisions on hire and lay off is usually based on collective bargaining agreements with regards to the production demand requirement. Also affecting workforce level are constraints imposed by labour law on employment or employee engagement which the organizations are bound to abide by; and union protests in shielding current employee. It is important also that organizational policy on hire and layoffs has to consider the availability of skilled workers that in some cases in more difficult to find compared to that of lower skilled worker, and recruiting them involves greater costs.

Developing the big data matrix attracts some associated costs. These cost estimates according to Banjoko, (2002) include cost from recruitment such as; screening, selection and training; cost from separation which includes severity package and its associated costs of readjusting the remaining workforce and finally, the indirect cost of low employee morale. These days, workers are seen as assets rather than variable costs and therefore managers of organizations will not likely apply layoff policy especially in specialized skill employees, for instance automated machine operators.

Overtime/slack time is the other essential strategic alternative used in adjusting employees' utilization to match with varying output levels. It is a more useful approach adopted when adjusting capacity to meet demand. Despite its usefulness, overtime may result in decreased 
productivity, decline in quality, increased accidents, production errors and increased payroll costs while on the other hand, slack \or idle time causes underutilization and inefficient use of machines and other fixed assets.

A firm may accept employment stability, especially where jobs are critical and skills scarce. Here employees are stable, and inventory adjusted as to maintain fluctuation in demand. Other firms use employees to maintain the expected aggregate output level by varying the workforce size as to hire and fire employees. When higher demand levels are anticipated, employees are hired to meet such demand increases. When demand is low, employees are fired-changes in employee level as a response to varied output levels.

\section{PRODUCTION EFFICIENCY}

In the previous section, we discussed the big data matrix and its strategic role in workforce level determination. Here, we will examine each of the specific measures of production efficiency as employee productivity and capacity utilization and the intervening variables of flexibility and lead time.

Lovell (2011) describes the efficiency of a production unit by comparing the observed and best possible values of its output and efforts. It is the measurement of the degree to which the production level is optimally assigned between the firms in the short run. An efficient productive outcome uses the least cost input mix required to produce a given output. A firm can possibly attain efficiency in production with its existing fixed assets without any significant increase in unit costs by taking appropriate decisions as a result of the application of workforce big data analytics, thereby, influencing an approximate scheduling of the workforce in achieving high levels of employee output and the resultant level of capacity utilization.

\section{Employee Productivity}

Productivity measures the relationship between outputs produced and inputs in the form of labour, capital, material and other resources (Hill, 2000).

The labour productivity data is shown on the performance of the manufacturing through increase in efficiency firm while contributing to the firm's market share and acting as a key factor in the comparative success of firms.

Production Managers are mostly occupied with operational tasks such as scheduling to maintain optimal utilization and efficiency levels, monitoring, controlling and resolving floor labour issues. However, the task of managing production has moved from the traditional production routine of product range, product mix, volume changes, process flexibility, inventory, and production cost to a more demanding challenge of maximizing the work force matrix in achieving the big-data complexity of employee awareness due to the implication of globalization on labour demand.

To perform the needed task complexities in the production process, the effective application of the big-data employ matrices are imperative to the production efficiency of manufacturing firms. Productivity is seen as one of the key index for determining the efficiency of business units in transforming inputs into outputs (Chen and Liaw, 2001). Productivity measured in man-hours, ensures that labour used in the production process are effectively utilized in converting input to output.

Just as the economic growth of a country is ascertained by its increase in production or the gross domestic product (GDP), which comes from a larger quantity of production factors used 
(inputs) and/or an increase in productivity (Output), likewise, in the manufacturing sector, productivity is seen as a key component of growth. To the manufacturing firm, the productivity measure can be used by production managers to evaluate production efficiency, and in thus the extent the concept of big-data utilization of the firm have been met.

Increase in productivity is ascertained when the quantity of inputs decreases while the quantity of goods and services produced remain constant, or the amount of goods and services produced is boosted with the same quantity of inputs. Productivity is usually clarified to mean the simple ratio of output to input. Productivity goes up when there is more output for the same resource input or the same output with a lower resource input.

A commonly widely used measure of productivity is employee productivity, measured in terms of output per employee or per man-hour. However, productivity can be examined in terms of the full range of production factors - capital, labour (employee) and intermediate goods and services. This is known as total productivity (Craig and Harris, 1973; Sumanth, 1984). Others are total factor productivity (Taylor and Davis, 1977) and capital productivity (Craig and Harris, 1973; Sumanth, 1984).

\section{Capacity Utilization}

The utilization rate is also expressed as the system efficiency (SE). It is the measure with which the firm's actual output which depends on the production capacity is described. The capacity utilization rate or the production system efficiency varies with the employee workforce levels employed in the production process.

The economic significance of capacity utilization can be expressed in the level of demand. If market demand grows, capacity utilization will rise as it is expected that output will increase. Also, if demand decreases, capacity utilization will likely reduce. This can be explained as a function of the big-data management of the employee levels in the production process.

The average rate of capacity utilization rate is about 44 per cent, and comparatively low with international standards (UNIDO, 2015). Identifying the capacity utilization rate can provide evidence in taking decisions on the long run expansion required of the firm especially in situations of increase in demand that can be accommodated by the increase output levels. This may create employment opportunities especially where increases in output is matched with a corresponding increase in the demand for the firm's product.

\section{Flexibility}

Flexibility is the responsiveness to changes in level of workforce that can match the required employee data in response to change in mix of products and services for the consumption of the customer. Changes in consumer tastes influence demand levels and the product variety needed. Manufacturing firms are expected to respond to demand uncertainties such as increase or decrease in output levels. It needs to be able to act in response to these alterations with appropriate employee matrix flexibility in product delivery in meeting customers' demand and to remain competitive in the market.

Flexibility has been well recognized as one of the answers to attaining competitive edge for any manufacturing firm. It is particularly important in addressing the current challenges in the manufacturing environment with an increasing domination of high employee mix and low volume production, increased customer expectations, increased uncertainty in customer behaviour along with the prevailing uncertainties (Chang, Yang and Wen, 2002). Firms then 
turn to redundancy and retrenchment as high employee mix creates disequilibrium on low production volume due to harsh economic environment experienced by manufacturing firms in Nigeria.

Walter, Sommer, and Zimmermann,(2011) stated that the goal of flexibility is to enable manufacturing firms to plan, monitor and manage the workforce level in response to minimizing resources, particularly in situations when future demands are not easy to anticipate and error acceptance is rather small.

\section{Lead time reduction}

Addressing on-time delivery expects the firm to pay concentrate to the cycle time involved in their existing products as well as in developing new products. The manufacturing firm also has to pay attention to its workforce scheduling and capacity planning to meet on-time delivery dates. The time covering when the customer places an order to when the customer receives the order is an increasingly important part of the production cycle (Dumaine, 2009). The bigdata analytics is one of several methods for reducing lead time and improving the overall performance of the manufacturing firm.

Furthermore, the firm should be dependable. Dependability is, of course, about consistency in meeting promised delivery deadlines for a product or service. However, it is worthy to note that customers may not be satisfied by swift delivery speed if it doesn't follow a consistent performance pattern.

\section{RESEARCH METHODOLOGY}

A survey identifying twenty (20) manufacturing firms registered with the Manufacturers Association of Nigeria (MAN) in Rivers State Nigeria as at September, 2016 was carried out. Due to the purpose of the survey, the sample used were 20 Production Managers each representing each of the manufacturing firms. The Production Managers were used because of the supervisory role they play in the Production floor and the fact that they are the front liners responsible for taking decisions that would influence the performance of the production department.

The questionnaire was simple structured with 5 distinct questions or items of 'Yes' and 'No' responses, except for the fifth question that gave room for respondents to choose options. A total of 20 copies of questionnaires were distributed and retrieved. The 20 copies of questionnaires retrieved were accurately completed representing $100 \%$ response rate. This value (20) was therefore used as the sample size in the data presentation and data analysis.

\section{Research Question}

To what extent does workforce big data analytics influence production efficiency?

The items below were used to provide data to address the research question. 
Summary of Items Responses

\begin{tabular}{|c|c|c|c|c|c|}
\hline $\mathbf{S} / \mathbf{N}$ & QUESTION & YES & $\%$ & NO & $\%$ \\
\hline & Workforce Analytics & & & & \\
\hline 1 & $\begin{array}{l}\text { Does your organization have a well understood } \\
\text { workforce planning framework? }\end{array}$ & 6 & 30 & 14 & 70 \\
\hline 2 & $\begin{array}{l}\text { Is the production department a major focus when it } \\
\text { comes to workforce planning and analytics? }\end{array}$ & 6 & 30 & 14 & 70 \\
\hline 3 & $\begin{array}{l}\text { Is it necessary to combine more than one business } \\
\text { process data when taking workforce scheduling } \\
\text { decisions? }\end{array}$ & 5 & 25 & 15 & 75 \\
\hline
\end{tabular}

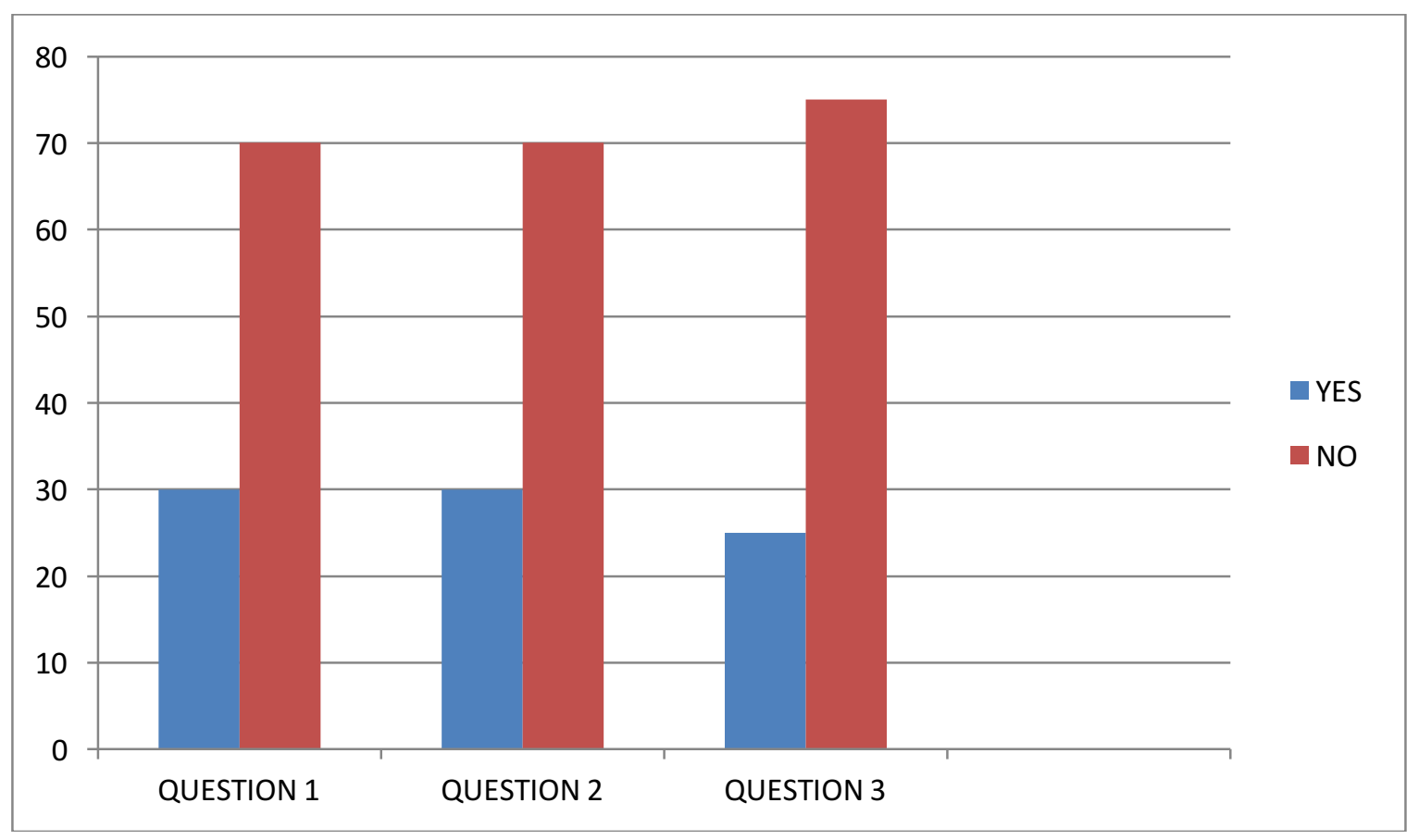

Corresponding bar chart item responses

\begin{tabular}{|l|l|c|c|c|c|}
\hline \multicolumn{1}{|c|}{ Production Efficiency } & $\begin{array}{c}\text { Above } \\
\text { Average }\end{array}$ & \% & $\begin{array}{c}\text { Below } \\
\text { Average }\end{array}$ & $\%$ \\
\hline 4 & $\begin{array}{l}\text { What is the current level of utilization of your } \\
\text { company's production capacity? }\end{array}$ & 5 & 25 & 15 & 75 \\
\hline
\end{tabular}




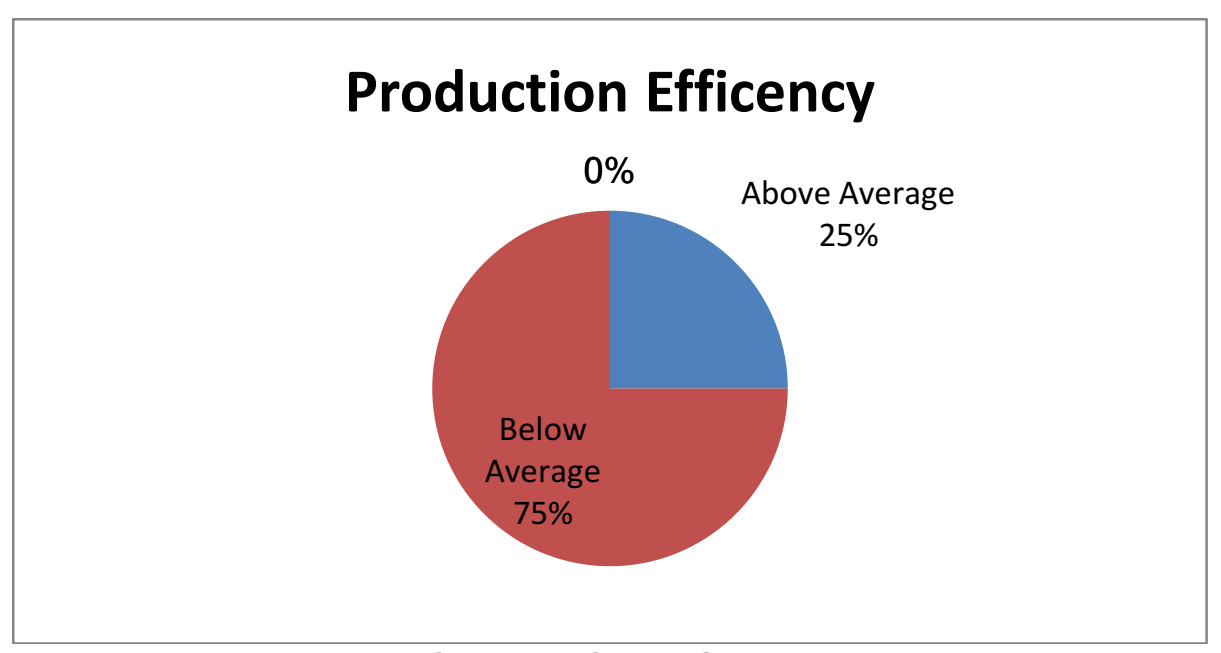

Corresponding pie chart of item responses

\begin{tabular}{|c|c|c|}
\hline Reasons & $\begin{array}{c}\text { No of } \\
\text { Responses }\end{array}$ & $\%$ \\
\hline Lack of adequate supply of raw materials & 2 & 13.3 \\
\hline $\begin{array}{l}\text { Excessive manpower downtime e.g. absenteeism, accidents, lockouts, } \\
\text { strikes, illnesses, attrition etc) }\end{array}$ & 6 & 40.0 \\
\hline Excessive machine downtime & 2 & 13.3 \\
\hline $\begin{array}{l}\text { Other reasons e.g. strike action, low productivity levels of employees, } \\
\text { employees' transport problems, materials/products }\end{array}$ & 5 & 33.3 \\
\hline
\end{tabular}

Source: From research study, 2016

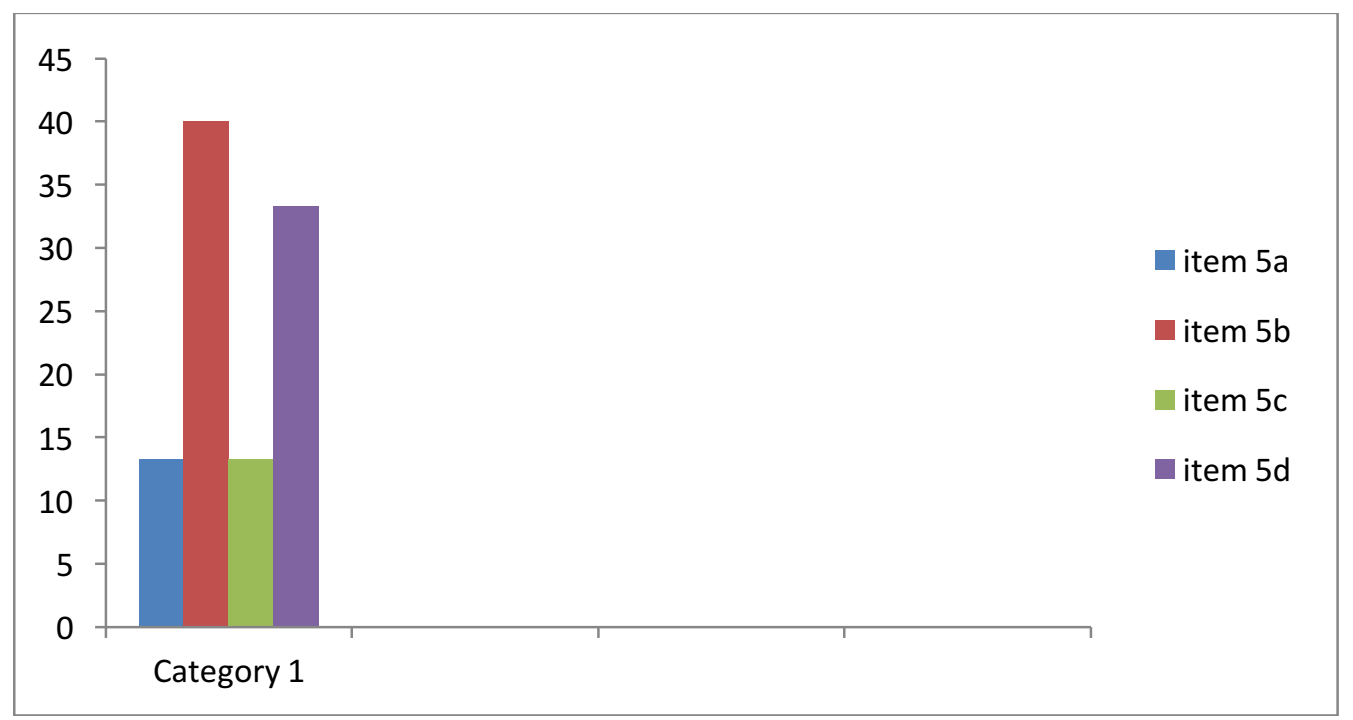

Corresponding bar chart item responses

From the Table above, only 30\% of the 20 Production Managers surveyed agreed that their firms have an established and understood workforce planning system (workforce analytics) in place while 70\% disagreed. Again from item 3, 25\% of the respondents agreed that workforce analytics is necessary while $75 \%$ disagreed that it is necessary. For Production Efficiency, only $25 \%$ admitted that their firms were operating above average while $75 \%$ said that their firms were operating below average. From the 15 production Managers who admitted that their firms were operating below average, $13.3 \%$ chose 'Lack of adequate supply of raw materials' as the reason for the below average performance; 40\% picked 'Excessive manpower downtime' (absenteeism, accidents, lockouts, strikes, illnesses, attrition) as the reason for their below 
average performance; $13.3 \%$ said 'Excessive machine downtime' was responsible for their below average performance and $33.3 \%$ said that it was reasons such as strike action, low productivity levels of employees, employees' transport problems, materials/products that was responsible for their below average performance.

Based on the result presented, we can see that the number of Managers that admitted that they have workforce analytics in place for their production unit (which is the summary of items 1 to 3 ) is very small compared to those who said they do not have any in place, subsequently, the number of Managers who agreed that they were operating at a below average level is higher than those operating at above average. This clearly indicates a linear relationship that the more firms make use of workforce analytics, the more their production efficiency. This can also be deduced from the fact that most of the reasons responsible for the firms to operate below average bothered mostly on manpower as shown from the responses presented.

From the result of the analyses above, it is adequate to establish that workforce big data analytics influence production efficiency of the firms which addresses the research question.

\section{CONCLUSIONS}

It has been established that one of the major challenge faced by the Production Manager is the task of attaining production efficiency in which goods and services are produced at the possible lowest cost. There seems to be a challenge in achieving this objective by the Production Manager because it involves the use of manpower in combination with machines. Being that the employees are endowed with capacities and deficiencies and machines are prune to breakdown, the Production Manager is constantly constrained to make decisions that would maximize these potentials or capacities and accommodate the deficiencies such that workers and machines are utilized at the best possible capacity.

Thus, workforce analytics attempts to put into consideration the human competences and deficiencies when planning the workforce to ensure efficiency. Work analytics is concerned with adapting the system to cost reductions, time reduction, new production and optimized offerings and smart decision making. It seeks to guide the decisions of the manager such that the right number of manpower is scheduled at the right time to minimize cost and maximize production.

Firms are yet to embrace the use of workforce analytics because it is still a complexity to them. This is in agreement with the low result gotten from firms making use of workforce analytics. The reason for this can be traced to the analytics capability and knowledge gap amongst managers in production unit.

\section{RECOMMENDATIONS}

Operations Managers need to pay critical attention to how they can harness the use of manpower and machine through workforce analytics such that efficiency in production is attained and maintained. It is also imperative that Managers seek to bridge their knowledge and capability gap in the use workforce analytics in production management through training. Operations Managers should constantly seek for the right and appropriate workforce metrics required for production management.

\section{Reference}

Banjoko, S. A. (2002). Production and Operations Management. Nigeria: Pumark Nigeria Limited.

Beal, V. (2015). Big-data, http://www.webopedia.com/TERM/B/big_data.html. 
Bassi, L. (2011). Raging debates in hr analytics. People and Strategy, 34(2), 14.

Carlson, K. D., \& Kavanagh, M. J. (2011). HR metrics and workforce analytics. Human Resource Information Systems: Basics, Applications, and Future Directions, 150.

Chang, C.C., Yang, H.M., \& Wen, J.C. (2002). Estimation of total flavonoid content in propolis by two complementary colorimetric methods J. Food Drug Anal., 10 (2), 178-182

Chen, L.H. \& Liaw, Y.S (2001) "Using financial factors to investigate productivity: an empirical study in Taiwan. Industrial Management and Data System, 101(7), 378-384.

Craig, C. E. \& Harris, C. R. (1973). Total Productivity Measurement at the Firm Level. Sloan Management Review. 14(3).13.

Du Plessis, A. J. (2009). An overview of the influence of globalization and internationalization on domestic Human Resource Management in New Zealand. International Review of Business Research Papers, 5(2), 1-18.

Dumaine, B. (2009). How managers can succeed through speed. Fortune, 13.

Everett, E.R, Eatherley, D. \& Slater, S. (1992). Competitiveness Improvements Potentially Available from Resource Efficiency Savings, report for Defra.

Fitz-Enz, J \& Mattox, J. (2014). Predictive analytics for human resources. Wiley publishers NY.

Hill, W. (2000). Strategic Management: Formulation, Implementation and Control New York McGraw-Hill.

Lawler, E.E., Levenson, A.R., \& Boudreau, J.W. (2005). HR metrics and analytics: Use and impact. Human Resource Planning, 27(4), 27-35.

Lovell, S.J. (2011). The economic contribution of marine angler expenditures in the United States, retrieved from http://www.st.nmfs.noaa.gov/economics/index.

Missildine, C (2013), From HR Metrics to HR Intelligence. HR Examiner, New York, Prentice Hall

Porter, M. E. (1998). The Competitive Advantage: Creating and Sustaining Superior Performance. NY: Free Press, 1985. (Republished with a new introduction.)

Sumanth, D. J., (1984) Productivity Engineering and Management, McGraw- Hill Book Company, New York.

Taylor, B.W. \& Davis, R.K., (1977). Corporate Productivity-Getting It All Together, Industrial Engineering, 9 (3).

Ulrich, K. T. (2013). Product Design and Development. New York: McGraw-Hill.

United Nations Industrial Development Organization (UNIDO) 2015, Lima Declaration adopted at the fifteenth session to promote and accelerate inclusive and sustainable industrial development (ISID) in developing countries and economies in transition.

Walter, M., Sommer, T.D.\& Zimmermann, J. (2011) Evaluating volume flexibility instruments by design-ofexperiments methods International Journal of Production Research, 49 (6), 1731-1752

Williams, J. S (2012). Introduction to management science, 3rd ed. Burr Ridge, IL. Richard D. Irwin 